\title{
ESSENTIAL NORM OF THE DIFFERENCES OF COMPOSITION OPERATORS ON THE BLOCH SPACE
}

\author{
YECHENG SHI AND SONGXIAO Li
}

Abstract. We provide some estimates for the essential norm of the differences of composition operators $C_{\varphi}-C_{\psi}$ acting on the Bloch space by using pseudo-hyperbolic distance, Möbius transformation and $\varphi^{n}-\psi^{n}$.

Mathematics subject classification (2010): 30H30, 47B33.

Keywords and phrases: Bloch space, difference, composition operator.

\section{REFERENCES}

[1] E. Berkson, Composition operators isolated in the uniform operator topology, Proc. Amer. Math. Soc. 81 (2) (1981), 230-232.

[2] C. Cowen and B. Maccluer, Composition Operators on Spaces of Analytic Functions, CRC Press, Boca Raton, FL, 1995.

[3] T. HosoKawa AND S. OHNo, Differences of composition operators on the Bloch spaces, J. Operator Theory 57 (2007), 229-242.

[4] S. Li, Differences of generalized composition operators on the Bloch space, J. Math. Anal. Appl. 394 (2012), 706-711.

[5] M. LindSTRÖM AND E. WOLF, Essential norm of the difference of weighted composition operators, Monatsh. Math. 153 (2008), 133-143.

[6] K. Madigan And A. Matheson, Compact composition operators on the Bloch space, Trans. Amer. Math. Soc. 347 (1995), 2679-2687.

[7] A. Montes-RodríGueZ, The essential norm of a composition operator on Bloch spaces, Pacific J. Math. 188 (1999), 339-351.

[8] P. Nieminen, Compact differences of composition operators on Bloch and Lipschitz spaces, Comput. Method Funct. Theory 7 (2007), 325-344.

[9] J. SHAPIRO AND C. SUNDBERG, Isolation amongst the composition operators, Pacific J. Math. 145 (1990), 117-152.

[10] M. TJANI, Compact composition operators on some Möbius invariant Banach space, $\mathrm{PhD}$ dissertation, Michigan State University, 1996.

[11] M. TJani, Compact composition operators on Besov spaces, Trans. Amer. Math. Soc. 355 (2003), 4683-4698.

[12] H. Wulan, D. Zheng And K. Zhu, Compact composition operators on BMOA and the Bloch space, Proc. Amer. Math. Soc. 137 (2009), 3861-3868.

[13] K. YANG AND Z. ZHOU, Essential norm of the difference of composition operators on Bloch space, Czech. Math. J. 60 (2010), 1139-1152.

[14] R. ZhaO, Essential norms of composition operators between Bloch type spaces, Proc. Amer. Math. Soc. 138 (2010), 2537-2546.

[15] K. ZHU, Operator Theory in Function Spaces, American Mathematical Society, Providence, RI, 2007. 